\section{Dire needs post earthquake}

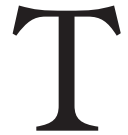

he Oct. 8 earthquake in South Asia destroyed 26 hospitals and 600 clinics, claiming the lives of 54000 people, including health care workers.

Eight days later, aid organizations were still unearthing bodies and treating victims.

Médecins Sans Frontières had 7 mobile medical teams in the rural areas around Islamabad, Pakistan, treating about 250 people a day with open fractures, "terrible infections," wounds and contusions.

"We haven't even started to look at the minor medical needs," Stephan Grosse Rueschkamp, a MSF press officer in Islamabad said in a phone interview.

There are Ioo MSF workers, including 3 Canadians (a mental health expert, logistician and financial coordinator) on site.

MSF is setting up psychosocial support for people who have lost family members, particularly children who have lost their parents. Grosse Rueschkamp said "no one has come to terms with what's happened in their families."

Speed is essential now with winter on its way. "There is snow in the

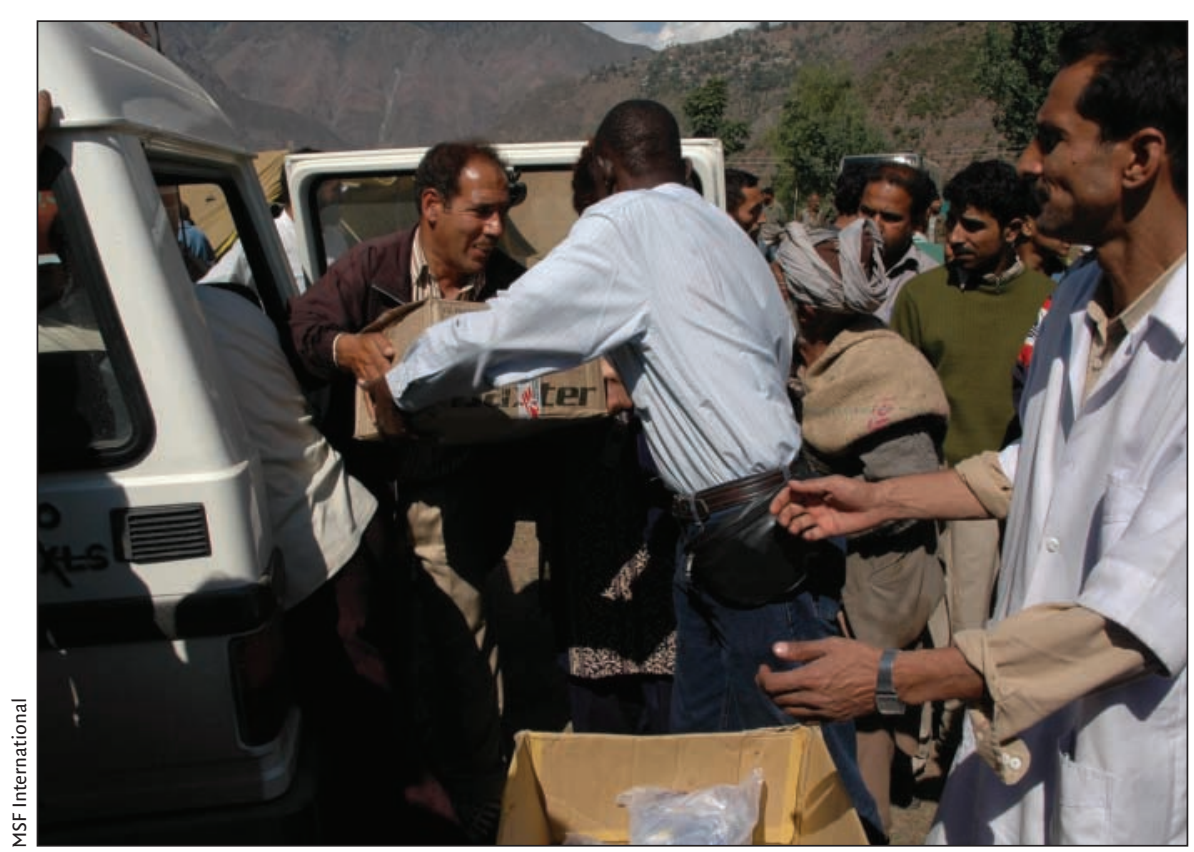

MSF has delivered 50000 blankets, chlorination kits, 20000 jerry cans and other supplies.

mountains," Grosse Rueschkamp said. "Exposure will lead to major health problems. We're running against the clock now."

MSF has delivered 1200 winterized tents, although an estimated 300000 are needed to help accommodate the estimated 4 million homeless.

The Canadian International Development Agency has earmarked \$20 million for disaster relief and the Canadian Red Cross has sent medical teams and II truck loads of tents and other supplies to Kashmir.

For the first time, 4 Canadian aid agencies have joined forces to raise money (CMAJ 2005;172:734). They include CARE Canada, Save the Children Canada, Oxfam Canada and OxfamQuebec.

WHO has sent emergency health kits to meet the basic needs of 270000 people for one month and surgical kits for 1000 surgeries. Four emergency teams with 6o WHO staff are working in the area.

Given that water and sanitation systems were heavily damaged, WHO is worried about the risk of diarrhoeal diseases. Measles is also endemic in the area, and only $60 \%$ of children are protected. - Barbara Sibbald, CMAJ

\section{DOI:I0.1503/cmaj.051346}

\section{Canada resists banning}

\section{flame retardant}

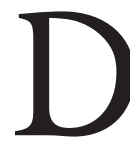

espite a growing number of peer-reviewed studies charting the toxicity of brominated flame retardant (BFR) in animals and possibly humans, the Canadian government remains reluctant to ban it.

The European Union (EU) banned 2 of the 3 commercially produced BFRs in 2002, and the states of California and New York have since followed suit. However, Steven Clarkson, director of Health Canada's Environmental Contaminants Bureau, is not ready to press for a ban. "There are still no definite conclusions available regarding human health effects," Clarkson says, "so in the case of the flame retardant formulations banned elsewhere, we are relying on chemical manufacturers to voluntarily switch to new products."

Scientists from around the world gathered in Toronto in August to present new studies on the toxicity of BFRs, which are widely used in computers, television sets, carpets and furniture foams.

BFRs began attracting scientific concern in the I980s when Swedish researchers first reported BFR contamination in human blood and breast milk at levels approaching those of polychlorinated biphenyls (PCBs) - a class of chemicals similar in molecular structure to BFRs. PCBS were banned as probable human carcinogens in the late I970s after they proved carcinogenic in animals.

Many observers suggest voluntary BFR control may be insufficient in light of new studies confirming that large amounts of BFRs are released from furniture, carpets and electronics in homes and offices.

"There has been a tremendous increase in the amount of information available regarding endocrine disruption in rats, fish and birds," says Linda Birnbaum, director of the US Environmental Protection Agency's National Health and Environmental Effects Research Laboratory. "I have a great deal of confidence in the relevance of these animal studies to humans," Birnbaum told CMAJ.

In a study reviewing human exposure levels and health effects (Organohalogen Compd 2004;66:395I-7), Tom Muir, a 